\title{
SIXTH INTERNATIONAL FESTIVAL OF RED CROSS AND HEALTH FILMS
}

The Sixth International Festival of Red Cross and Health Films was held at Varna, Bulgaria, from 16 to 25 June 1975. More than 300 films from some forty-five countries were shown.

The Festival, which was organized by the Bulgarian Red Cross in co-operation with the League of Red Cross Societies, had the patronage of the League and the World Health Organization. Bulgarian government authorities, members of the diplomatic corps and numerous representatives of the Red Cross, film, television and medical and health fields attended the opening ceremony held in Varna's Palace of Sports and Culture.

The Varna biennial festival brought together the best Red Cross and health films made in recent years by National Societies, film and television companies, studios, universities, medical institutes and health organizations. For the first time, there was a special showing of amateur films to encourage the production of films on subjects related to the Red Cross and health. Another innovation this year was a "film market", organized in co-operation with the Bulgarian Cinematographic Office, which enabled film users to acquire the best and most recent films in their fields of interest.

On the closing day, five Grands Prix were awarded. The Grand Prix of the President of the Bulgarian Red Cross went to a short film, The Parable of the Wheel (USSR), and the League's Grand Prix to The Street and Man (Yugoslavia). Various other prizes and medals were awarded to short films, feature films and television films. 